\title{
التتاحية العدد
}

\author{
أدد. محمد محمد اللهادي \\ رئيس مجلس الإدارة
}

وقد يواجه شخص ما بقضية تتعلق بواصفات البيانات اللغوية التي قد تتوازن مع تساؤل

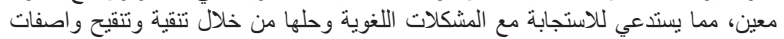

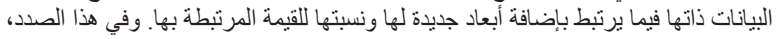

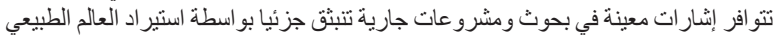

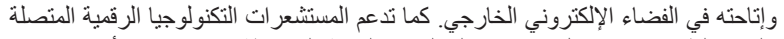

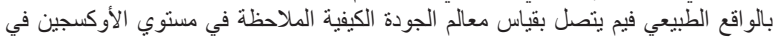

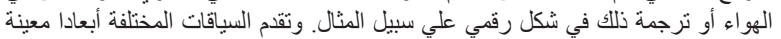

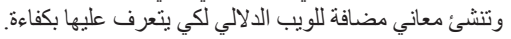

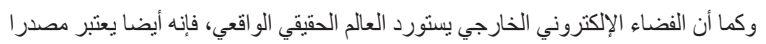

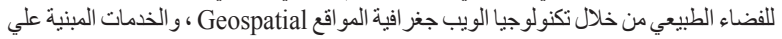

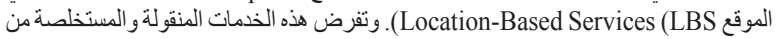

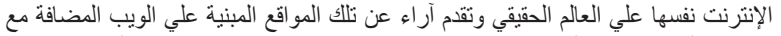

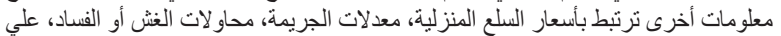

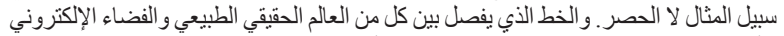

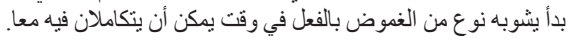

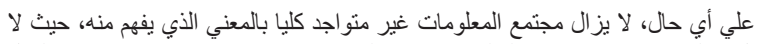

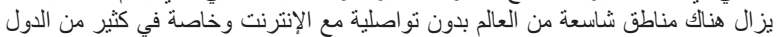

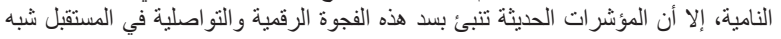

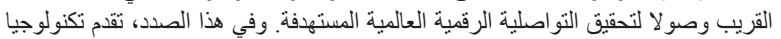

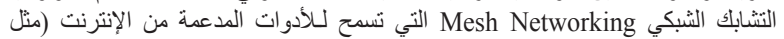

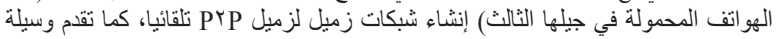

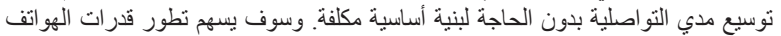

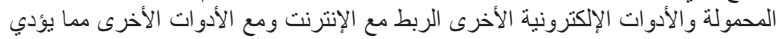

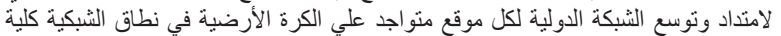

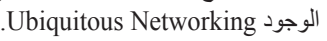

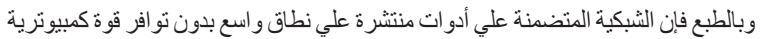

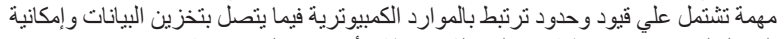

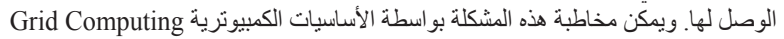

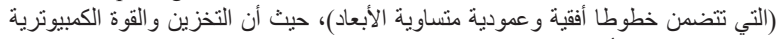

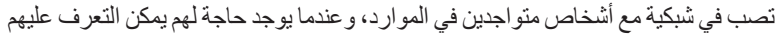

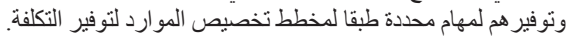

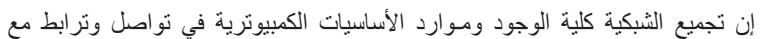

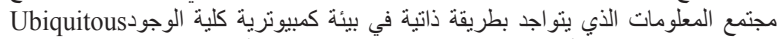

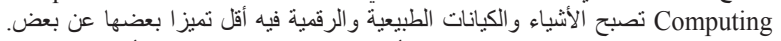

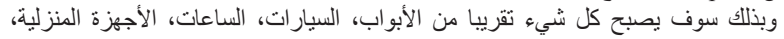

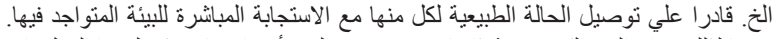

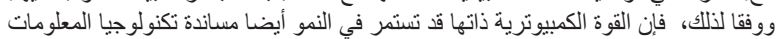

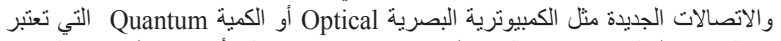

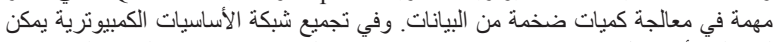

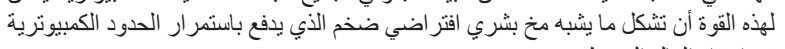
في امتداد العالم المحيط.

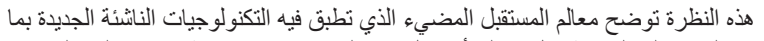

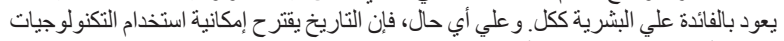
الناشئة أيضا في تغيير مسار أداء المهام البشرية بكفاءة وفعالية تحقق الغايات الإيجابية وتحد من السلبيات أينما تتو اجد.

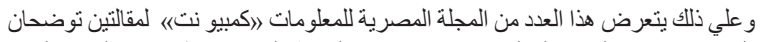

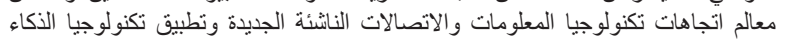
الاصطناعي في نظم التعليم الر اهنة.

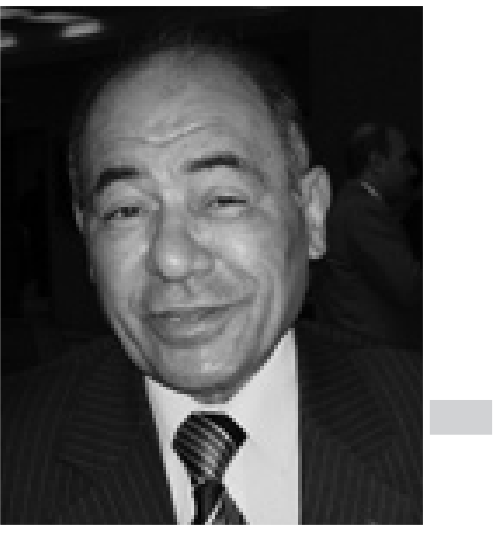

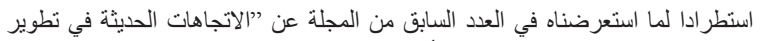

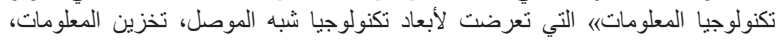

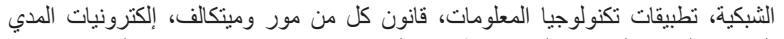

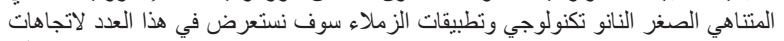

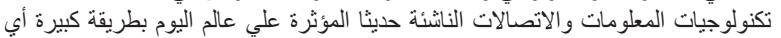

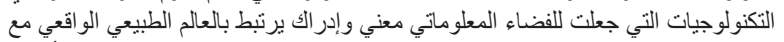

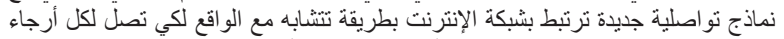

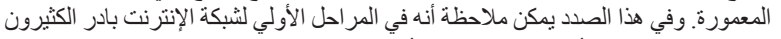

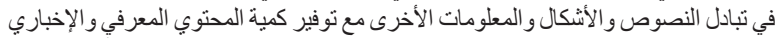

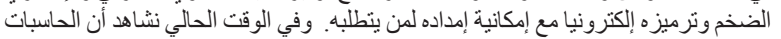

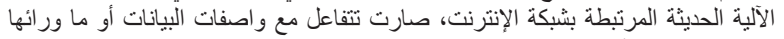
Metadata الإنترنت الدلالي Semantic Web الذي يقام مو اصفات البيانات أو البيانات عن البيانات لتبات لتحديد

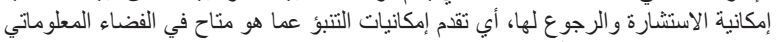

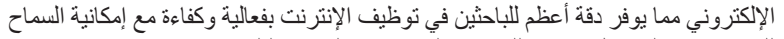
للحاسبات في الوصول مباثرة للمحتوي المستهدف و والقيام بتحليلها.

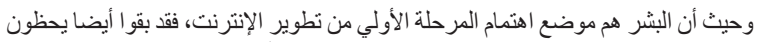

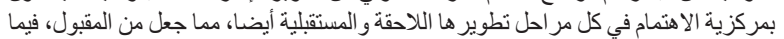

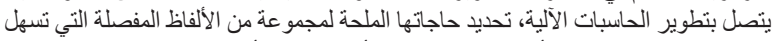

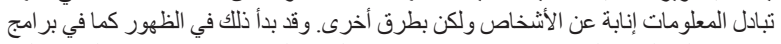

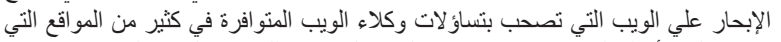

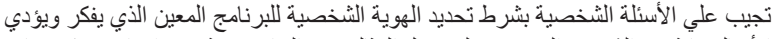

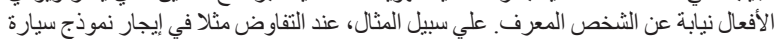

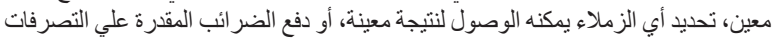

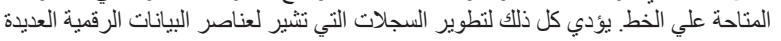

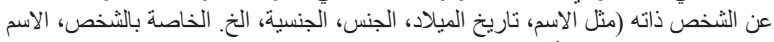

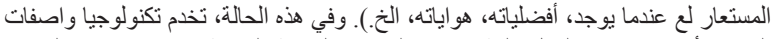

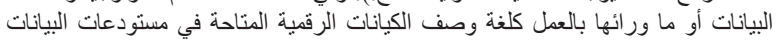
المتشعبة المتو افرة علي شبكة الإنترنت.

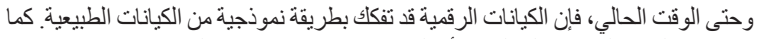

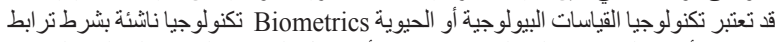

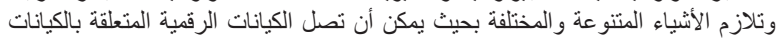

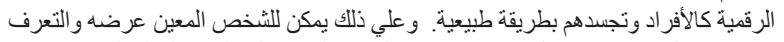

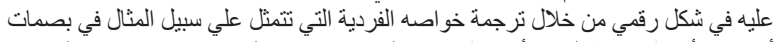

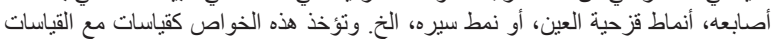

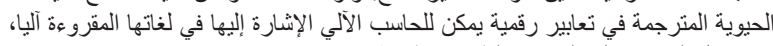

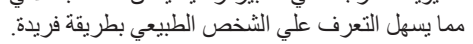

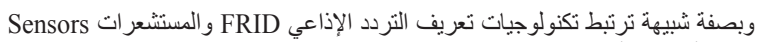

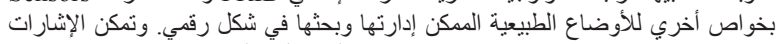

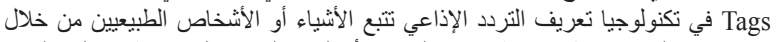

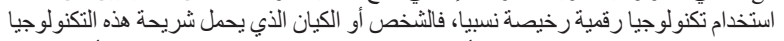

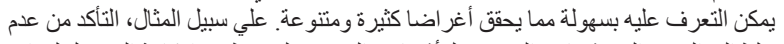

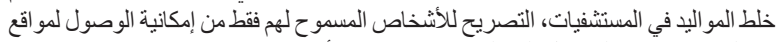

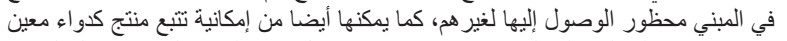

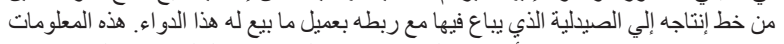

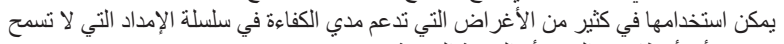
بحدوث أي أخطاء في المنتج أو الخدمة المقدمة. 